Session 2230

\title{
UPDATE ON IMPEC: AN INTEGRATED FIRST-YEAR ENGINEERING CURRICULUM AT N.C. STATE UNIVERSITY
}

\author{
Richard M. Felder, Robert J. Beichner, Leonhard E. Bernold, \\ Ernest E. Burniston, Philip R. Dail, Hugh Fuller \\ North Carolina State University
}

An integrated freshman engineering curriculum called IMPEC (Integrated Mathematics, Physics, Engineering, and Chemistry Curriculum) has undergone three years of pilot-testing at North Carolina State University under the sponsorship of the SUCCEED Coalition. In each semester of IMPEC, the students take a calculus course, a science course (chemistry in the first semester, physics in the second), and a one-credit engineering course. The curriculum is taught by a multidisciplinary team of professors using a combination of traditional lecturing and alternative instructional methods including cooperative learning, activity-based class sessions, and extensive use of computer simulations. The goals of the curriculum are to provide motivation and context for the fundamental material taught in the first-year mathematics and science courses, a realistic and positive orientation to the engineering profession, and training in the problem-solving, study, and communication skills that correlate with success in engineering school and equip individuals to be lifelong learners. This paper summarizes program assessment and evaluation results and describes plans to export features of IMPEC into the regular first-year engineering curriculum.

\section{Curriculum Structure and Instructional Approach}

The principal features of IMPEC are as follows:

- In the fall semester, the students take a four-credit introductory calculus course, a three-credit general chemistry course with an additional one-credit laboratory, and a one-credit engineering course. In the spring semester, they take a second four-credit calculus course, a four-credit physics course (mechanics), and a second one-credit engineering course. The calculus, chemistry, and physics courses parallel those in the regular curriculum. The fall engineering course replaces the standard freshman orientation course, and the spring engineering course is an add-on to the standard curriculum.

- The courses are team-taught by mathematics, chemistry, physics, and engineering professors, who present fundamental scientific and mathematical material in the context of real-world problems to the greatest extent possible. As a rule only one professor at a time is in the classroom, but several times during each semester the entire IMPEC faculty is present to conduct a "workshop" on a topic that involves all of the disciplines being taught. The faculty meets periodically, in person and electronically, to coordinate assignments, schedule activities, and discuss any problems that the students seem to be having. 
- With the exception of the chemistry laboratory, the courses are taught in a single classroom equipped with PC's that have real-time data acquisition capability. The classroom holds 36 students, thus limiting the enrollment in IMPEC.

- The calculus instruction follows the Harvard Calculus format, emphasizing a true understanding of concepts as opposed to learning drills and prescriptions. The "rule of three" is followed, which states that every topic should be presented geometrically, numerically, and algebraically. A symbolic mathematics application program (MAPLE) is used for complex calculations and graphing.

- In the chemistry course, multimedia instructional packages-Exploring Chemistry and Introduction to General Chemistry, distributed by Falcon Software- supplement the standard textbook. The students are routinely called upon in class to provide evidence of their conceptual understanding, with emphasis being placed on questions that involve analysis, synthesis, and evaluation. In the laboratory the students are not given detailed procedures for most exercises but have to work out the details themselves in teams (except for matters related to safety). The lecture and laboratory components of the course are integrated to a much greater extent than in the standard curriculum.

- In physics, variations on ideas in Workshop Physics (Priscilla Laws, Dickinson College) and Studio Physics (Jack Wilson, RPI) are used to create hands-on exercises to illustrate physical concepts. Flexible microcomputer-based laboratory tools are used for acquisition, reduction, and real-time plotting of experimental data. Computer simulations and spreadsheets are also used as instructional tools. Homework and test questions are frequently open-ended, demanding more than formula substitution for solutions.

- Features of the engineering courses include guided exercises and homework assignments that require applying calculus, chemistry, and physics concepts and techniques to engineering problems; training in study and time-management skills, word processing and other computer applications, technical writing, oral presentations, and presentation graphics (PowerPoint); assignments that involve summarizing sections and doing chapter-end exercises in Studying Engineering by Raymond Landis; orientation presentations by representatives of different engineering departments; field trips to engineering laboratories and a construction site; guest presentations by recent engineering graduates; and team projects that involve elementary engineering design and analysis, application of principles from the science and calculus courses, and preparation of oral and written project reports.

- A nominal schedule states which courses meet during which hours, but the actual schedule changes every week according to which topics are to be emphasized. Most class periods are taught by individual IMPEC faculty members, but several times during each semester "workshops" on specific topics (e.g. statistical analysis and angular motion) are team-taught by the full faculty.

- The course instruction makes extensive use of active (experiential) and cooperative (teambased) learning and other methods designed to address the full spectrum of student learning styles, ${ }^{1}$ reducing but not completely eliminating formal lecturing. All laboratory experiments and most homework and in-class activities are done by teams of students. Exercises are 
designed to provide positive interdependence, individual accountability, and periodic selfassessment of team functioning.

- Homework and examinations contain a mixture of closed (single-answer) problems designed to test understanding of specific methods and skills as well as open-ended multidisciplinary questions to foster the students' creativity and ability to integrate the full range of course material.

- Course handouts, assignments, and revised schedules are delivered via an IMPEC home page on the World Wide Web. Most students feel no need to print the materials, since they can consult the web site for a current version from computers in the classroom or their dormitories at any time. Distributing the course materials in this manner is no more timeconsuming than the traditional process of making paper copies, and the inevitable last-minute changes are effortless.

\section{Enrollment and Retention Data}

In each of the three years IMPEC has been offered, several hundred randomly selected entering freshmen were invited to attend a presentation on the program at the University's summer orientation program for entering students. We used a stratified random selection to enroll 36 of these students in IMPEC (the maximum capacity of our classroom), attempting to match the population demographics and average admissions index (a predicted grade-point average used at N.C. State) of the entire entering class. Outcomes for the past two academic years and the one currently in progress are as follows:

- Year 1: 1994-95. Nine students got D's or F's in at least one of the fall semester courses, making them ineligible to continue in IMPEC; seven passed all courses in the fall with grades of $\mathrm{C}$ or better but chose not to re-enroll in the spring; and 18 completed the two-term sequence with grades of $\mathrm{C}$ or better in all courses, for a $50 \%$ successful completion rate for the year. No minority students chose to enroll in the class. Comparison data for students in the regular freshman engineering curriculum are not available.

- Year 2: 1995-96. Nine students got D's or F's in at least one of the fall courses; two passed in the fall but chose not to enroll in the spring; and 25 completed the two-term sequence with grades of $\mathrm{C}$ or better in all courses, for a $69 \%$ completion rate for the year. The comparable figure for the 736 students in the regular freshman orientation class (E100) was 52\%, and that for a control group of 31 students (to be described shortly) was also 52\%. All four of the African-American students in IMPEC were successful, as compared to three out of the nine African-American students in E100. Six out of the ten women in IMPEC were successful, as compared to $51 \%$ of the women in E100.

- Year 3: 1996-97. In the fall semester only one student got a grade lower than $C$ in any of the sequence courses, and the remaining 35 re-enrolled in the spring. As this paper is being written, about six students are struggling with second-semester calculus and three are having difficulties with physics, but we still anticipate a high completion rate compared with the average for the entire freshman class. 
We are not sure why this year's class is doing so well compared to the previous classes, but we can speculate. One possibility is that we are learning by trial-and-error how to deliver an integrated curriculum, which is not something faculty members are trained to do. Another is that this class - for reasons that may have little or nothing to do with anything the faculty has doneseems to have cohered personally to a much greater extent than the previous ones did. They try to take the same courses outside of IMPEC, some share apartments, some even share clothing. When the cooperative learning teams were given the option of disbanding after the first month and forming new groups, every team in the class chose to remain together, unlike last year when one-third of the groups disbanded. If one believes the precepts of cooperative learning (which we do), improved social cohesion should lead to improved academic performance.

\section{Assessment and Evaluation}

The 1994-95 version of IMPEC did not parallel the standard freshman engineering curriculum (it included two semesters of physics and no chemistry), and the decision was made not to perform a full assessment of the program in that year. In 1995-1996, an extensive assessment program was undertaken. Data were compiled for IMPEC students and (unless otherwise noted) students in two comparison groups. The term "Control Group" refers to a group of 31 students who volunteered for IMPEC but were not selected due to the capacity of the IMPEC classroom. They matched the IMPEC group in pre-college performance measures, but did not include any African-American students. The term "E100 group" refers to the 736 students in the regular freshman engineering course, including nine African-American students. (Most of the other African-American students in the freshman class were in a separate program designed specifically for minorities.)

The data compiled included the following:

- $\quad$ re-admission data (predicted grade-point average, SAT scores).

- responses to the "Attitude Survey about Engineering" (beginning and end of the fall semester, and for IMPEC only, end of the second semester). An instrument developed at the University of Pittsburgh that assesses attitudes toward engineering as a curriculum and career, self-reported confidence levels in core freshman-year subjects, and in the postsurvey, attitudes toward the freshman year experience.

- Force Concept Inventory scores (IMPEC only, beginning and end of second semester). A widely used instrument that assesses conceptual understanding of mechanics.

- performance on common final exam problems in calculus, chemistry, and physics courses.

- responses to open-ended questions on midsemester and end-of-semester surveys (IMPEC only).

- Written and oral engineering project reports (IMPEC only)

- Passing rates in calculus and science courses included in IMPEC.

- Overall GPA in the first year.

- Retention in engineering through the first year. 
Following is a summary of the principal results for the 1995-96 year.

- The pass rate ( $\mathrm{C}$ or better) in the core courses was significantly higher for IMPEC students $(69 \%)$ than for students in the control group (52\%) or in E100 (52\%). Roughly equal percentages of all three groups (roughly 80\%) remained as declared engineering majors at the beginning of the Fall 1996 semester, but fewer of the IMPEC students were in academic difficulty.

- IMPEC students did as well as or better than students in the control groups on common final examination questions in calculus, chemistry, and physics courses. The IMPEC students also did well on questions that tested them for the deeper levels of comprehension of principles that were among IMPEC's principal objectives. (We had no way of including such questions on the final examinations in the traditionally-taught courses.)

- The IMPEC students' performance on the Force Concept Inventory was substantially better than the average performance of students at other institutions who had taken a traditionallytaught lecture-based mechanics course.

- When the students were asked to indicate their agreement or disagreement with the statement, "I expect engineering will be a rewarding career," the IMPEC students and the control and E100 groups all strongly agreed at the beginning of the fall semester. A decline in the average level of agreement would be expected during the first semester, since most entering students have little or no idea of what engineering is and some find that they are poorly suited to it. At the end of the semester, the average levels of agreement for the control and E100 groups declined two to four times more sharply than that of the IMPEC students, which only declined slightly.

- The IMPEC students' level of agreement with the statement, "The engineering course helped me know whether I want to major in engineering," was significantly greater than the levels of agreement of the control group and the E100 group.

- To a much greater extent than students in the regular freshman engineering course, the IMPEC students credited their engineering course with helping them improve their skills in problem solving, studying, teamwork, time management, reading, writing, speaking, and computing.

- The IMPEC students' self-rated confidence in their abilities in chemistry, engineering, computing, speaking, and writing increased sharply in the first semester. The confidence levels of the control students in the same areas declined (dramatically in chemistry and writing, slightly in engineering, computing, and speaking). The confidence levels of the E100 students either declined sharply (in chemistry), stayed roughly the same (in engineering), or increased slightly (in computing, speaking, and writing).

- The IMPEC students slightly increased their confidence in their calculus ability in the first semester. The E100 students (a number of whom had taken advanced placement calculus in high school) maintained but did not increase their confidence, and the control group confidence sharply declined. 
- The IMPEC students' confidence in physics increased slightly in the first semester, which is interesting since none of them took a physics course that semester. It may be that their increased confidence in other areas simply made them more confident of their problemsolving abilities in general, regardless of the subject, or that the emphasis on applications in the Harvard Calculus approach increased their confidence in their ability to deal with physics problems. Their confidence in physics increased sharply after they took the physics course in the second semester.

The positive attitudes of the IMPEC students to almost every aspect of the course are all the more impressive considering that they found the curriculum more demanding than the control and E100 groups found their freshman year curricula (as evidenced by their responses to certain questions on the Attitudes about Engineering survey).

Quantitative elaborations of these results are contained in a report to the National Science Foundation, available upon request from the authors. ${ }^{2}$ Data for $1996-1997$ will be presented at the June meeting.

\section{Exporting IMPEC features to the regular first-year engineering curriculum.}

The resource demands of IMPEC (primarily faculty time and dedicated computer-equipped classroom space) make it difficult to contemplate implementing the entire curriculum model for a substantial fraction of the roughly 1000 students in the first year of engineering at N.C. State. A number of IMPEC's features are exportable, however, and steps have already begun to implement them. Primary among these features is the use of engineering-based problems to illustrate and integrate curriculum fundamentals and provide practice in computer applications, explicit training in critical study and communication skills, systematic assessment of student performance and attitudes using a standardized instrument, and block scheduling of courses so that student cohorts can remain together to form what the cooperative learning theorists call "base groups." Elements of the project-based approach used in the IMPEC chemistry laboratory have been adopted for general use by the N.C. State Chemistry Department, and an effort is underway in the Physics Department to adopt the hands-on instructional approach used in IMPEC. These efforts will be continued and expanded in the coming year.

\section{Acknowledgments}

IMPEC is supported by the National Science Foundation SUCCEED Coalition. We are indebted to Ben O'Neal and John Risley for their contributions to planning the program, to John Gastineau for developing and implementing the physics instructional model used in the first two years of IMPEC, to Peg Gjertsen for invaluable assistance with computer operations and networking, and to Jackie Dietz, Gary Felder, Diane Hall, and Meredith Mauney for their help in designing and implementing the program assessment and evaluation. 


\section{References}

1. R.M. Felder, "Matters of Style," ASEE Prism, 6(4), 18-23 (1996).

2. R.M. Felder, L.E. Bernold, E.E. Burniston, P.R. Dail, H.D. Fuller, and J.E. Gastineau, IMPEC-Integrated Mathematics, Physics, Engineering, and Chemistry Curriculum: 1996 Annual Report, November 1996.

RICHARD M. FELDER is the Hoechst Celanese Professor of Chemical Engineering at North Carolina State University. He is co-author of the introductory chemical engineering text, Elementary Principles of Chemical Processes and codirector of the National Effective Teaching Institute. His papers on various aspects of engineering education can be viewed at http://www2.ncsu.edu/effective_teaching/.

ROBERT J. BEICHNER is Assistant Professor of Physics at North Carolina State University. His interests center on research and development of technology for physics instruction. Further information can be found at http://www2.ncsu.edu/ncsu/pams/physics/People/beichner.html

LEONHARD E. BERNOLD is Associate Professor of Civil Engineering at North Carolina State University. He is the founder and director of the Construction Automation and Robotics Laboratory at N.C. State, teaches courses in construction engineering and management, and conducts research related to both his technical specialties and to learning and teaching styles in engineering education.

ERNEST E. BURNISTON is Professor of Mathematics at North Carolina State University. His education-related interests include mathematics curriculum reform and educational uses of technology. Further information can be found at http://www4.ncsu.edu/eos/users/e/eeb/www/

PHILIP R. DAIL is Coordinator of Advising of the College of Textiles at North Carolina State University and has taught chemistry at both the high school and university levels. He won the 1988 Presidential Award in Science Teaching, the 1990 Tandy Technology National Science Teaching Award, and the 1991Ciba Geigy Chemistry Teacher of the Year Award. He is the director of the 1997 National Science Olympiad Tournament.

HUGH FULLER is the Director of Educational Assessment for the College of Engineering at North Carolina State University. 